\title{
Microstructure Evolution of AZ80 Magnesium Alloy during Multi-Directional Forging Process
}

\author{
Qingfeng Zhu*, Lei Li, Zhiqiang Zhang, Zhihao Zhao, Yubo Zuo and Jianzhong Cui \\ Key Laboratory of Electromagnetic Processing of Materials, Ministry of Education, \\ P. O. Box 314, Northeastern University, Shenyang 110004, P. R. China
}

Grain refinement of a magnesium alloy, AZ80, was studied in multi-directional forging (MDF) with decreasing temperatures from 683 to $573 \mathrm{~K}$. The MDF was carried out up to accumulative true strains of around 7 with changing the loading direction from pass to pass. The structural changes are characterized by the alternate appearance of fine dynamic recrystallized (DRXed) grains (with many dynamic granular $\mathrm{Mg}_{17} \mathrm{Al}_{12}$ phases) and coarse DRXed grains (without $\mathrm{Mg}_{17} \mathrm{Al}_{12}$ phases) in the sample, the expansion of the fine grains area, and the refinement of (DRXed) grains in the fine grains area during the MDF process. The non-uniform dynamic precipitation of the $\mathrm{Mg}_{17} \mathrm{Al}_{12}$ phase may attribute to the inhomogenous $\mathrm{Al}$ content distribution in the $\mathrm{Mg}$ matrix. These $\mathrm{Mg}_{17} \mathrm{Al}_{12}$ phase retards the growth of the DRX grains, which in turn results in the formation and the expansion of the fine grains area during the MDF process with decreasing temperature.

[doi:10.2320/matertrans.M2013251]

(Received July 3, 2013; Accepted November 5, 2013; Published January 25, 2014)

Keywords: AZ80 magnesium alloy, multi-directional forging, severe plastic deformation, dynamic recrystallization, precipitation

\section{Introduction}

Ultra-fine grain (UFG) structure materials are assumed to possess high strength and good ductility. To obtain such materials, severe plastic deformation (SPD) is the most effective method. As a widely used material in modern industry, Mg alloys have also been inevitably involved in the SPD process. So far, the SPD-induced fine grained microstructure and the corresponding properties of $\mathrm{Mg}$ alloys have been extensively reported. ${ }^{1-10)}$ It has been discussed that during cold or warm working the fine grains result from the continuous dynamic reactions. However, the grain size depends on the deforming temperature, strain rate, and original structure, etc.

Although a low deforming temperature is desirable for obtaining fine grains, the poor ductility of $\mathrm{Mg}$ alloys will induce fracture. Hence, taking into account both the grain refinement and the formability, the $\mathrm{SPD}$ of $\mathrm{Mg}$ alloy is usually carried out in a temperatures decreasing process with low strain rate. ${ }^{9-12)}$ In the AZ-series $\mathrm{Mg}$ alloys, the decreasing temperatures during the SPD process will lead to the reduction of aluminum solid solubility, and then result in the "dynamic precipitation" of the $\mathrm{Mg}_{17} \mathrm{Al}_{12}$ phase. This phase can reduce the final dynamic recrystallized (DRXed) grain size by pinning the grain boundaries. ${ }^{10)}$

In addition, it is known that original structure also has an important influence on the final deformed structure. Usually the original grains can be completely replaced by the DRXed grains by a continual increment of the strains during SPD. However, the original inhomogenous solute distribution (unavoidable even with a normal homogenized heat treatment ${ }^{13)}$ ) cannot be eliminated by this increment. As mentioned above, the $\mathrm{Mg}_{17} \mathrm{Al}_{12}$ phase in the AZ-series $\mathrm{Mg}$ alloys can affect the DRXed grains. Thus, the inhomogenously distributed $\mathrm{Al}$ and then the precipitated $\mathrm{Mg}_{17} \mathrm{Al}_{12}$ phase will certainly result in inhomogenously deformed structure.

*Corresponding author, E-mail: zhuqingfeng@epm.neu.edu.cn
AZ80 is an important deformation $\mathrm{Mg}$ alloy. The structure evolution of this alloy in the SPD process has been widely investigated. ${ }^{10,14)}$ However, the correlation among the Al solute distribution, the precipitation of $\mathrm{Mg}_{17} \mathrm{Al}_{12}$ and the DRXed grain size was rarely mentioned. Based on this, AZ80 $\mathrm{Mg}$ alloy was chosen and multi-directionally forged during decreasing temperatures from pass to pass and the abovementioned correlation was carefully studied.

\section{Experimental}

Three same-sized rectangular samples $(61 \mathrm{~mm}(x$ axis $) \times$ $52 \mathrm{~mm}$ ( $y$ axis $) \times 45 \mathrm{~mm}(z$ axis $))$ were cut from a commercial direct chill (DC) casting AZ80 magnesium alloy (annealed at $683 \mathrm{~K}$ for $16 \mathrm{~h}$ ) with compositions of $\mathrm{Al}$ (7.85 mass \%), Zn (0.43 mass\%), Mn (0.21 mass\%) and the balance $\mathrm{Mg}$. The samples were heated at $683 \mathrm{~K}$ for $1.5 \mathrm{~h}$, and then forged by a $300-t$ hydraulic press. The MDF process was carried out with changing the loading axes (i.e., $x \rightarrow y \rightarrow z \rightarrow x \ldots)$ from pass to pass. The strain rate and the true strain of each pass were $0.13 \mathrm{~s}^{-1}$ and 0.5 (with 0.5 true strain the sample could almost change back to the original shape in each pass, indicating that the MDF process could be carried out infinitely), respectively. The detailed experimental parameters are shown in Table 1. The deformed samples were cut along the middle plane parallel to the last compression axis, then mechanically polished and etched by the mixed liquid picric acid and nitric acid for macro- and microstructural observation. Afterwards, small specimens

Table 1 Experimental parameters.

\begin{tabular}{cccc}
\hline $\begin{array}{c}\text { Sample } \\
\text { number }\end{array}$ & $\begin{array}{c}\text { Forging } \\
\text { passes }\end{array}$ & $\begin{array}{c}\text { Final forging } \\
\text { temperature } \\
(T / \mathrm{K})\end{array}$ & $\begin{array}{c}\text { Accumulative } \\
\text { true strain } \\
(\varepsilon)\end{array}$ \\
\hline P4 & 4 & 608 & 2 \\
P7 & 7 & 598 & 3.5 \\
P14 & 14 & 573 & 7 \\
\hline
\end{tabular}




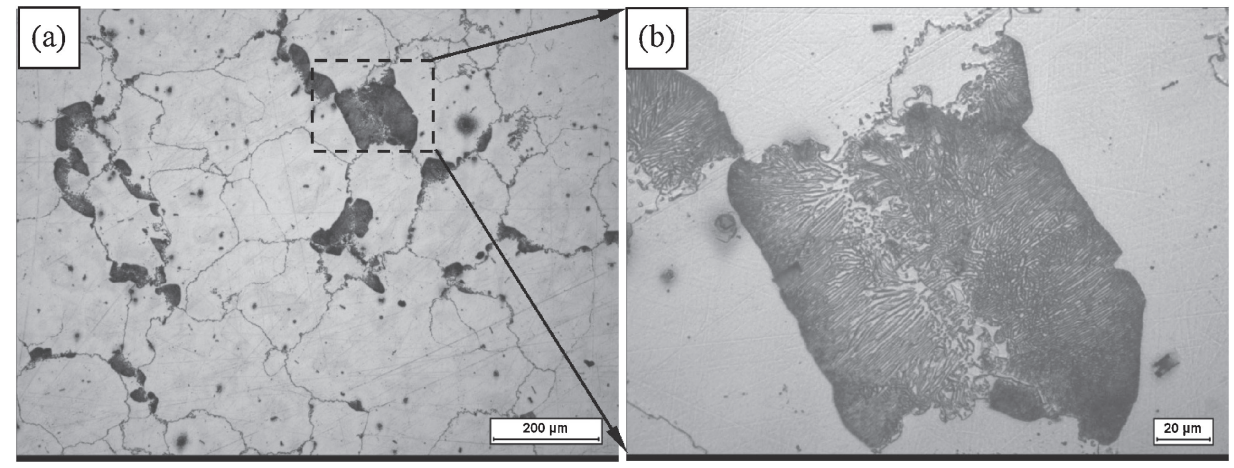

Fig. 1 Optical microscope images of as-homogenized AZ80 alloy specimen, and (b) magnified micrographs signed by the rectangular frame in (a).

were cut from these samples. With a further grounding, polishing and oxidizing, these specimens were observed by a SHIMADZU SS-550 scanning electron microscope. The $\mathrm{Al}$ and $\mathrm{Zn}$ compositions in the primary $\mathrm{Mg}$ matrix were manually detected by the EPMA-1600/1610 Electron Probe Microanalysis (EPMA).

\section{Results and Discussion}

Figure 1(a) shows the optical micrograph of the initial DC casting AZ80 alloy after homogenization heat treatment. It can be found that the matrix is composed of some equiaxed grains (about $210 \mu \mathrm{m}$ ). And some black contamination like substances are distributed along the grains boundaries. A further observation shows that these substances are composed of laminar second phase, as shown in the magnified figure in Fig. 1(b). EDX analysis indicates that the phase is laminar $\beta$ - $\mathrm{Mg}_{17} \mathrm{Al}_{12}$. A statistical measurement suggests that the mean area fraction of $\mathrm{Mg}_{17} \mathrm{Al}_{12}$ in the specimen is about $13.6 \%$.

Figures 2(a)-2(c) show the macrostructures of the specimens with different forging passes. As can be seen, the metal flow lines become more obvious with increasing the passes. To reveal the details, the microstructures corresponding to the zones enclosed by the rectangular frames in Figs. 2(a)-2(c) are displayed in Figs. 2(d)-2(f), respectively. It can be found that the metal flow lines are actually composed of some mutual-mixed black and white structures. Furthermore, the areas of the black structures increase with increasing the accumulative strains and decreasing temperature. The mean fractions of the black areas measured in Figs. 2(d)-2(f) are about $19.4,25.4$ and $52.2 \%$, respectively.

Figures 3(a)-3(c) show the further magnified micrographs of the P4-sample, P7-sample and P14-sample respectively. It can be seen that in all the samples the white and black structures consist of coarse (about $20 \mu \mathrm{m}$ ) and fine (several micrometers) grains, respectively. Moreover, the areas of the fine grains obviously increase with increasing the accumulative strains and decreasing temperature. A further observation indicates that some second-phase $\beta-\mathrm{Mg}_{17} \mathrm{Al}_{12}$ is distributed along the boundaries in the fine grain structure, as shown in the SEM images in Figs. 4(a)-4(c). And different from the laminar second-phase in the initial alloy, the $\beta$ $\mathrm{Mg}_{17} \mathrm{Al}_{12}$ reveals granular form. Moreover, the size of the

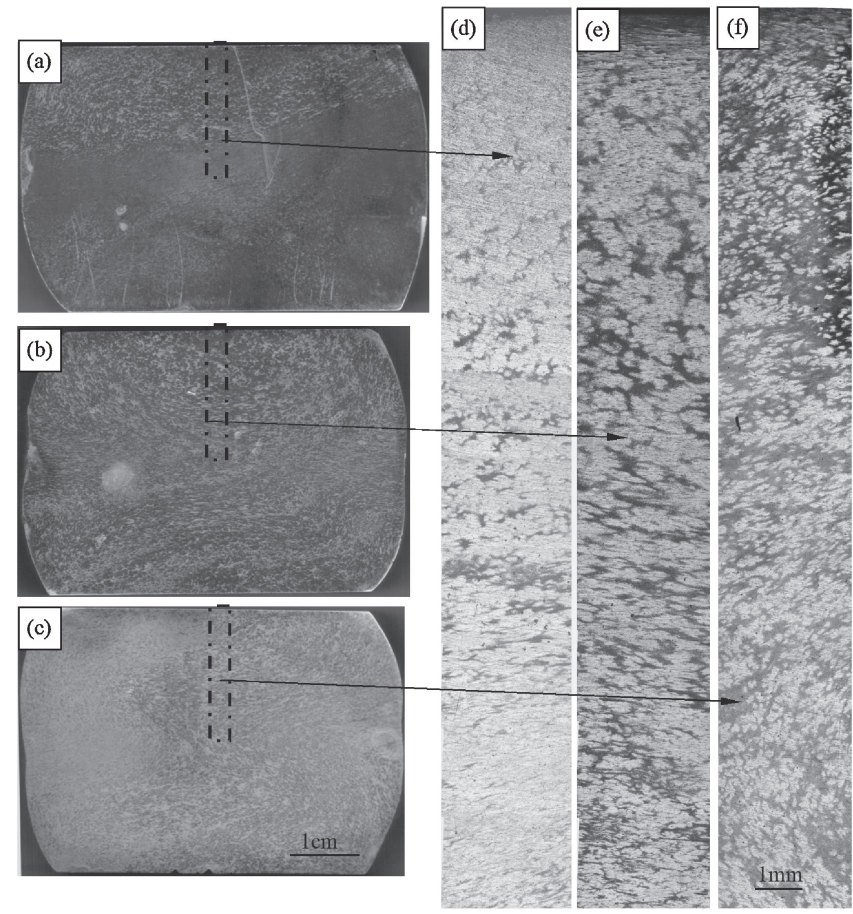

Fig. 2 Macro and micro-structure of the MDF samples, (a) P4-sample, (b) P7-sample, (c) P14-sample. (d) (e) and (f) are magnified micrographs signed by the rectangular frame in as signed by rectangular frames in the (a) (b) and (c) respectively.

fine grains decreases with increasing the accumulative strains and decreasing temperature, but that of the coarse grains seems less affected. In addition, it is also found that the $\mathrm{Al}$ compositions in the primary $\mathrm{Mg}$ matrix in the fine and coarse grains are also different. Figure 5(b) shows a typical zone with mixed fine and coarse grains. EPMA analysis on the points enclosed by the circles (see the magnified images in Figs. 5(a) and 5(c)) indicates that the mean $\mathrm{Al}$ compositions in the $\mathrm{Mg}$ matrix of fine and coarse grains are 8.1 and 6.1 mass $\%$, respectively.

The results have clearly shown that the existence of the granular $\beta-\mathrm{Mg}_{17} \mathrm{Al}_{12}$ phase on the grains boundaries retards the growth of the DRXed grains, and results in the formation of fine grains in the AZ80 alloy. B. Q. $\mathrm{Shi}^{10)}$ and $\mathrm{Xu}^{12)}$ have found a similar structure in the deformed AZ80 and AZ91 alloy respectively, and evidenced the function of $\beta-\mathrm{Mg}_{17} \mathrm{Al}_{12}$ 


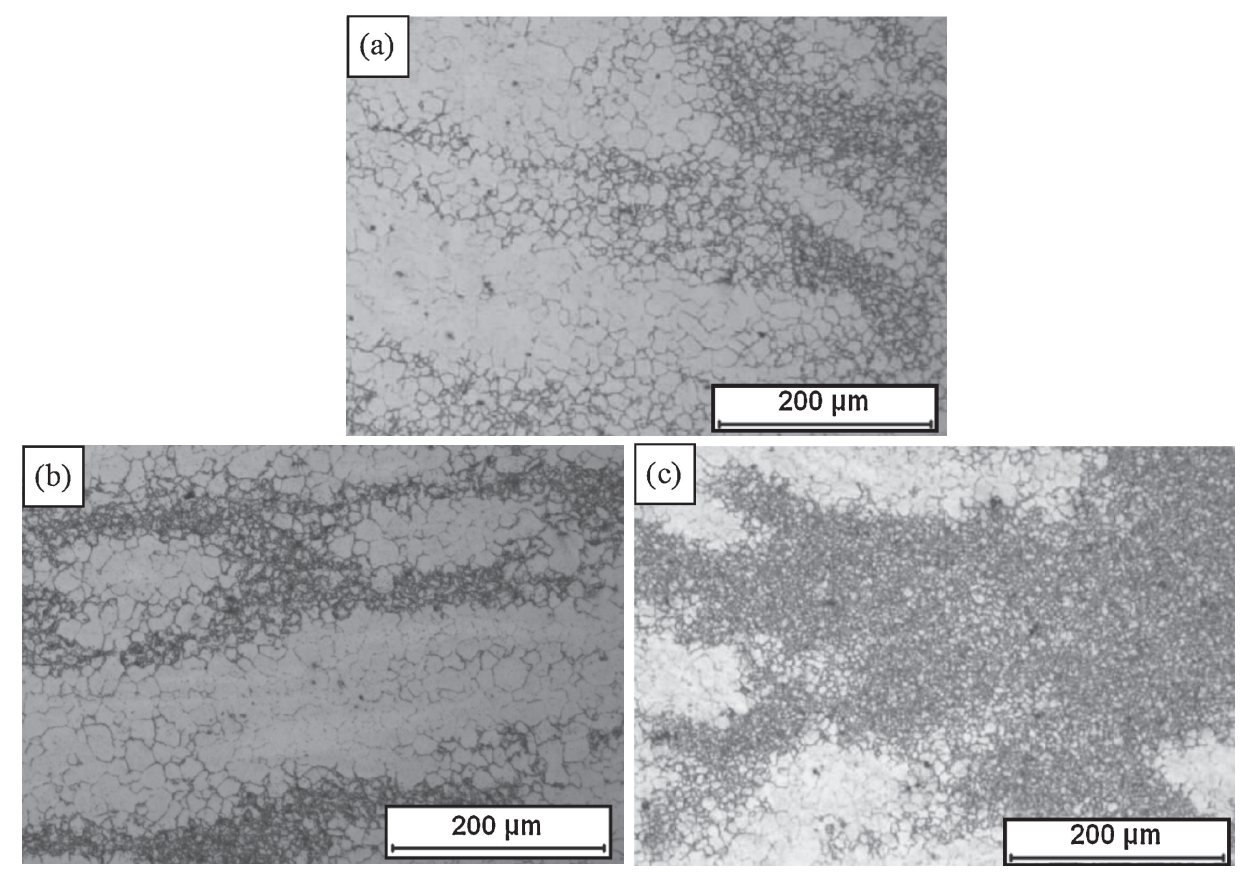

Fig. 3 Magnified micrograph of different deformed sample, (a) P4-sample, (b) P7-sample, (c) P14-sample.
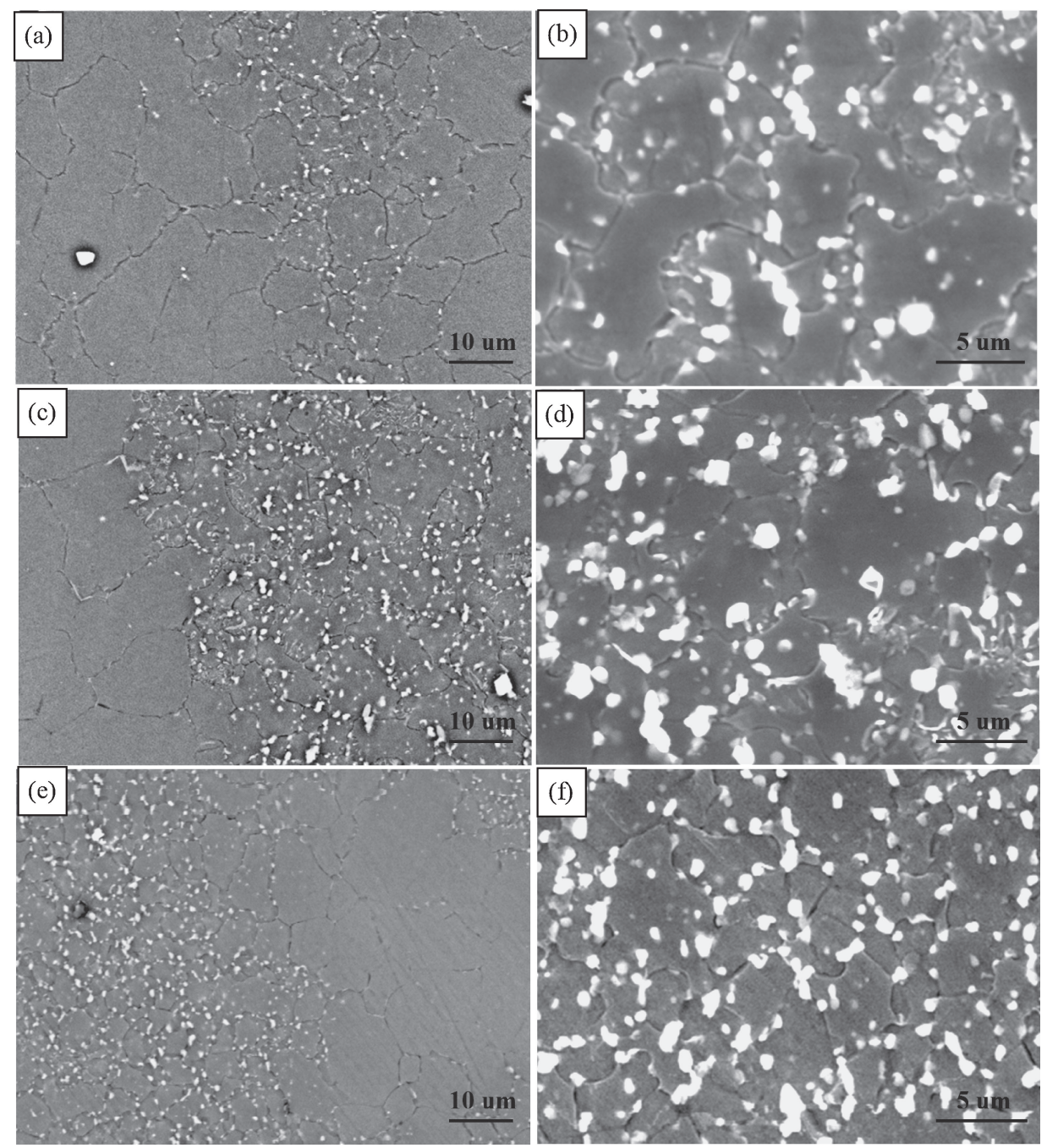

Fig. 4 SEM images of the samples, (a) P4-sample, (c) P7-sample, (e) P14-sample, (b) (d) and (f) are the partial magnified micrographs of fine grains area corresponding with (a) (c) and (e) respectively. 

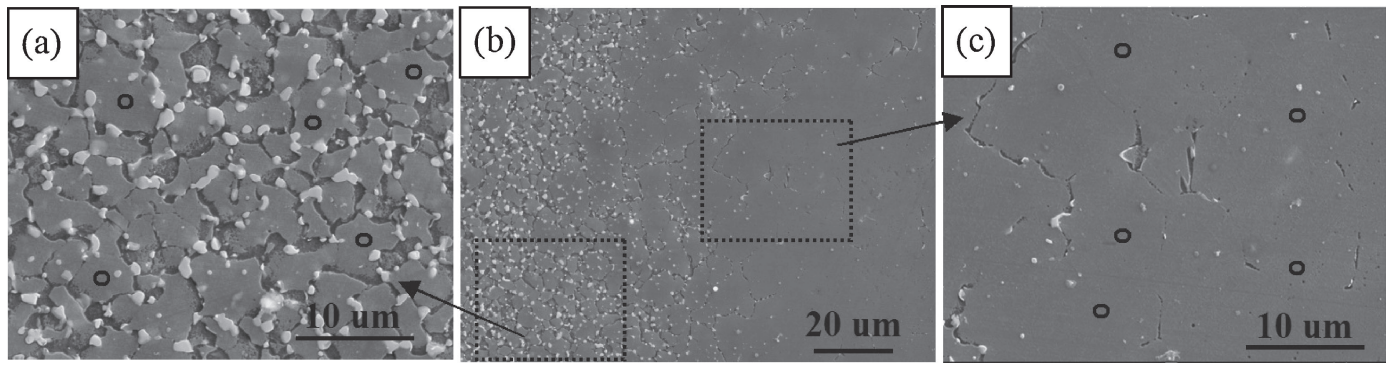

Fig. 5 Micro area of P14-sample measured by EPMA, (a) and (c) are the enlarged images as signed by the circles.

phase in retarding grains growth. Nevertheless, different viewpoints are proposed in the formation of the $\beta-\mathrm{Mg}_{17} \mathrm{Al}_{12}$ phase by them. $\mathrm{Xu}$ considered that the granular phase results from the crush of the originally formed $\mathrm{Mg}_{17} \mathrm{Al}_{12}$ phase in the alloy, whereas B. Q. Shi believed that it origins from the precipitation of $\mathrm{Mg}_{17} \mathrm{Al}_{12}$ phase during the MDF process. In the present work, the $\mathrm{Mg}_{17} \mathrm{Al}_{12}$ phase shows such a tendency that its area fractions increase in the fine grains area with increasing the accumulative strains and decreasing temperature. This may indirectly prove that the precipitation of $\mathrm{Mg}_{17} \mathrm{Al}_{12}$ phase is the main origin of the granular phases, which agrees with B. Q. Shi.

During the MDF process, the precipitation of $\mathrm{Mg}_{17} \mathrm{Al}_{12}$ phase should be affected by the deforming temperature, accumulative strains and $\mathrm{Al}$ content in the $\mathrm{Mg}$ matrix, etc. However, in a local micro area with and without $\mathrm{Mg}_{17} \mathrm{Al}_{12}$ phase, the deforming temperature and the accumulative strains should be approximately the same. Thus, the precipitation of $\mathrm{Mg}_{17} \mathrm{Al}_{12}$ phase should be mainly controlled by the $\mathrm{Al}$ content in the $\mathrm{Mg}$ matrix. As aforementioned, the solute distribution in the initial alloy is inhomogenous, which will naturally result in an ununiform precipitation of the $\mathrm{Mg}_{17} \mathrm{Al}_{12}$ phase. This has also been proved by the above-mentioned EPMA measurement that the mean $\mathrm{Al}$ composition in the $\mathrm{Mg}$ matrix of fine is higher than that in the coarse grains. As a consequence, fine and coarse grains coexist in the microstructures. It has been mentioned that the precipitation of the $\mathrm{Mg}_{17} \mathrm{Al}_{12}$ should be related to the accumulative strains and temperatures. However, in this work, it has been found that there is no clear difference in the precipitation amounts of the $\mathrm{Mg}_{17} \mathrm{Al}_{12}$ between the stagnant zone (near the hammerhead) and the easy deformation zone (the sample center) (see Fig. 6), where accumulative strains are obviously different in one sample. This may indirectly prove that the precipitation of the $\mathrm{Mg}_{17} \mathrm{Al}_{12}$ should be mainly determined by temperature changes, i.e., the precipitation amount of the phase is increased with decreasing the temperatures.

In summary, during the MDF process, the modification of the structures can be attributed to the interaction between the DRX and the dynamic precipitation of the $\mathrm{Mg}_{17} \mathrm{Al}_{12}$ phase. On one hand, the pinning effect of the $\mathrm{Mg}_{17} \mathrm{Al}_{12}$ phase can greatly retard the growth of the DRXed grains. On the other hand, the newly formed grain boundaries provide an ideal position for the precipitation of $\mathrm{Mg}_{17} \mathrm{Al}_{12}$ phase. Yet the interaction between these two aspects is complicated. A further study is needed to confirm the dominant factor in modifying the structures.

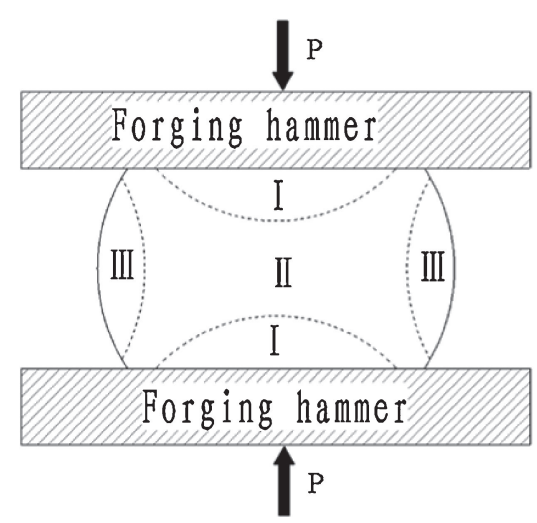

Fig. 6 Sketch illustrate of the three deformation zone in the free forging process, I stagnant zone, II easy deformation zone, III free deformation zone.

\section{Conclusion}

The AZ80 Mg alloy has been MDFed to the maximum accumulative true strains of 7 with decreasing temperature from 683 to $573 \mathrm{~K}$. Main conclusions obtained are shown as follows:

(1) In the present MDF process, the coexistence of the fine grains (with many granular $\mathrm{Mg}_{17} \mathrm{Al}_{12}$ phases) and coarse grains (without $\mathrm{Mg}_{17} \mathrm{Al}_{12}$ phases) is the main character of the structure.

(2) The fine grains area and the fraction of granular $\mathrm{Mg}_{17} \mathrm{Al}_{12}$ phases expand with the increasing accumulative strains and decreasing temperature.

(3) The size of the fine grains decreases with increasing the accumulative strains and decreasing temperature, but that of the coarse grains seems less affected.

(4) The inhomogenous $\mathrm{Al}$ content distribution in the $\mathrm{Mg}$ matrix leads to the non-uniform dynamic precipitation of the $\mathrm{Mg}_{17} \mathrm{Al}_{12}$ phase during the MDF process with temperature decreasing. These non-uniform distributed $\mathrm{Mg}_{17} \mathrm{Al}_{12}$ phases retard the growth of the DRX grains, which in turns results in the formation and the expansion of the fine grains area.

\section{Acknowledgement}

The project is supported by National Natural Science Foundation of China (No. 51204053 \& 51204048 \& 51074048), China Postdoctoral Science Foundation (No. 20110491518), National Program on Key Basic Research Project (973 Program) (No. 2012CB619506). 


\section{REFERENCES}

1) J. Xing, H. Soda, X. Yang, H. Miura and T. Sakai: Mater. Trans. 46 (2005) 1646-1650.

2) M. Kai, Z. Horita and T. G. Langdon: Mater. Sci. Eng. A 488 (2008) 117-124.

3) R. Lapovok, P. F. Thomson, R. Cottam and Y. Estrin: J. Mater. Sci. 40 (2005) 1699-1708.

4) H. Miura, X. Yang and T. Sakai: Mater. Trans. 49 (2008) 1015-1020.

5) H. K. Lin, J. C. Huang and T. G. Langdon: Mater. Sci. Eng. A 402 (2005) 250-257.

6) Y. Yoshida, L. Cisar, S. Kamado and Y. Kojima: Mater. Trans. 44 (2003) 468-475.

7) R. Z. Valiev, P. K. Islamgaliev and I. V. Alexandrov: Prog. Mater. Sci.
45 (2000) 103-189.

8) M. T. Pérez-Prado, J. A. Valle and O. A. Ruano: Mater. Sci. Eng. A 523 (2009) 47-52.

9) K. Matsubara, Y. Miyahara, Z. Horita and T. G. Langdon: Acta Mater. 51 (2003) 3073-3084.

10) B. Q. Shi, R. S. Chen and W. Ke: Mater. Sci. Eng. A 546 (2012) 323327.

11) H. Miura, G. Yu and X. Yang: Mater Sci. Eng. A 528 (2011) 69816992.

12) S. W. Xu, N. Matsumoto, S. Kamado, T. Honma and Y. Kojima: Scr. Mater. 61 (2009) 249-252.

13) S. W. Xu, S. Kamado and T. Honma: Mater. Sci. Eng. A 528 (2011) 2385-2393.

14) Q. Guo, H. G. Yan, Z. H. Chen and H. Zhang: Mater. Charact. 58 (2007) 162-167. 